\title{
The effects of drug administration to the lateral hypothalamus: Neurochemical coding or nonspecificity?**
}

\author{
SALVATORE CAPOBIANCO and DAMON MOUNTFORD \\ University of Kansas, Lawrence, Kansas 66044
}

\begin{abstract}
Adrenergic and cholinergic drugs were utilized to investigate receptor specificity in the lateral hypothalamic feeding and drinking systems. Natural hunger was not effectively reduced by adrenergic antagonism. Cholingergic agents elicited and blocked eating responses under different conditions. These results are interpreted as a lack of specificity and are discussed in terms of such a model.
\end{abstract}

The results of early studies indicated that the feedingand drinking-related fibers in the lateral hypothalamus (LH) may be functionally distinguished in terms of the substances utilized for synaptic transmission (Grossman, 1962). Although the hypothesis of chemically coded neural control of behavior has been subsequently well accepted, a number of recent investigators have reported nonspecific excitatory changes following direct application of drugs to the brain (Routtenberg, 1972; Singer \& Kelley, 1972). Perhaps the most important unresolved problem in chemical stimulation research is the apparent failure to adequately block deprivation-induced behavior states. Levitt \& Fisher (1967) found that atropine injected into sites at which cholinergic stimulation produces consistent drinking does not reduce deprivation-induced thirst. In view of these conflicting reports, an attempt was made to distinguish more completely the receptor specificity of LH sites which have been implicated in consummatory behaviors. Drugs specific to adrenergic receptors were utilized to investigate the feeding system, while cholinergic drugs were used to investigate the drinking system.

\section{METHOD}

The Ss were 15 male albino rats of the Sprague-Dawley strain obtained from Charles River Labs. The rats averaged 160 days of age and weighed approximately $350 \mathrm{~g}$ at the time of surgery. Sodium pentobarbital $(50 \mathrm{mg} / \mathrm{kg})$ was used as anesthesia. Bilateral cannulae were stereotaxically lowered into $\mathrm{LH}$, and affixed at the following deGroot (1959) coordinates: $\mathrm{A}=6.2, \mathrm{H}$ $=1.5, \mathrm{~L}=1.5$. Following completion of behavioral testing, standard histological procedures revealed that all but one rat had implant tips in the region of the LH.

\section{Procedure}

Preparation for chemical stimulation consisted of removing the inner cannula and cleaning it with alcohol and a fine wire:

*This research was completed at Kansas University by the first author, under the direction of the second author, in partial fulfillment of the requirements for the master's degree. Support was partially obtained through an NIMH predoctoral fellowship awarded to S. Capobianco (MH 47061-01). Requests should be sent to the first author, Department of Psychology, Rutgers University, New Brunswick, New Jersey 08903. This paper is sponsored by Leonard W. Hamilton, who assumes editorial responsibility for it.
Following this procedure, the drug was tapped into the tip of the cannula and returned to the implant site. The same procedures were used in control tests, with the exception that no drug was administered.

The drugs used under sated conditions were carbachol, norepinephrine, histamine, and isoproterenol. Deprived rats were treated with atropine, dibenzyline, diphenhydramine, propranolol, and sodium chloride following $18 \mathrm{~h}$ of deprivation. The drugs were administered in the order presented above in each case, with one-fourth (satiated) or one-fifth (deprived) of the rats starting the sequence of each drug. Dosages of drugs were in the range of 6-14 micrograms, except for carbachol, the dosage of which was restricted to approximately 1-2 micrograms.

Intake of food and water was measured at 30 -min intervals for $90 \mathrm{~min}$. Satiated rats were maintained in individual cages with free access to food and water. Control tests were given daily until stable baselines of intake were established (i.e., no significant change in either food or water intake for 3 consecutive days). The drug tests were initiated with 1 drug day being given every third day, preceded by two control days. The changes in food or water intake were assessed by "difference scores," obtained by subtracting the average of the control tests from the drug test. These scores were analyzed by a t test for related measures (Walker \& Lev, 1953). The animals tested under deprivation conditions were treated identically, with the exception that deprivation of both food and water was begun $18 \mathrm{~h}$ prior to testing.

\section{RESULTS AND DISCUSSION}

As shown in Panel A of Fig. 1, the direct application of norepinephrine and carbachol to $\mathrm{LH}$ in sated animals elicited a significant increase in food intake $(t=5.61, d f$ $=15, \mathrm{p}<.01$; and $\mathrm{t}=3.73$, df $=14, \mathrm{p}<.01)$. These results are consistent with those of other investigators who have implicated the cholinergic system in feeding behavior in the rat (Wise, 1972) and rabbit (Sommer et al, 1967). Large increases in water intake were found following injections of carbachol $(\mathrm{t}=4.88$, $\mathrm{df}=14$, $\mathrm{p}<.01)$, isoproterenol $(\mathrm{t}=5.79, \mathrm{df}=14, \mathrm{p}<.01)$, and histamine $(\mathrm{t}=3.51, \mathrm{df}=14, \mathrm{p}<.01)$. Since isoproterenol produced potent drinking effects, the notion of beta-adrenergic receptors mediating central drinking responses is supported (cf. Mountford, 1969). The possibility of histaminergic involvement in thirst is difficult to assess, since the actions of this drug were small, and the antagonist, diphenhydramine, failed to affect water intake. 


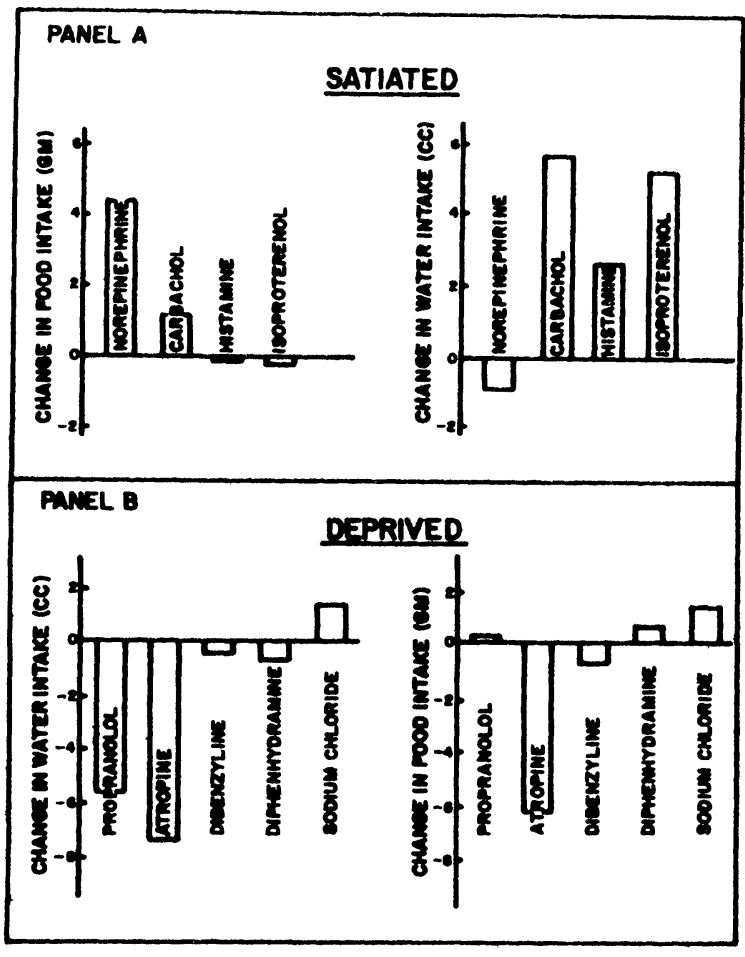

Fig. 1. Changes in food and water intake from control levels during $90 \mathrm{~min}$ immediately following direct application of drugs to lateral hypothalamus of sated and $18 \mathrm{~h}$ deprived rats.

Following $18 \mathrm{~h}$ of deprivation, atropine blocked water intake $(\mathrm{t}=6.41, \mathrm{df}=9, \mathrm{p}<.01)$, but at the same time, caused a large decrease in food intake $(\mathrm{t}=4.68, \mathrm{df}=9$, $p<.01)$. Grossman (1967) similarly reported that atropine significantly affected the performance of instrumental responses for food reward. Panel B of Fig. 1 shows that propranolol produced a significant decrease in water intake $(t=5.50, d f=9, p<.01)$, while sodium chloride produced a small increase in food intake $(t=2.35, \mathrm{df}=9, \mathrm{p}<.05)$. While the actions of the beta-antagonist, propranolol, were predictable, the increased feeding in response to sodium chloride may represent nonspecific excitation of neural tissue (Epstein, 1962).

Several recent investigations have suggested that consummatory behavior induced by direct chemical stimulation may not be as precise as has been previously thought (Wise, 1972). Although most data indicate a noradrenergic feeding system, it has been found that cholinergic stimulation also results rather consistently in eliciting feeding responses, and cholinergic blockade will reduce neurochemically induced, as well as natural hunger (Singer \& Kelley, 1972). A model not unlike the Burn-Rand hypothesis (i.e., adrenergic stimulation mediated by cholinergic neurons) was proposed by Singer and Kelley (1972), to account for these effects. The present findings are consistent with such a notion. Further, it is suggested that the substrate activated by chemical stimulation, and those active during natural thirst may not both be identical (Mountford, 1969; Levitt \& Fisher, 1967). The status of this question was evaluated in a recent review (Singer \& Montgomery, 1973). It was concluded that the data, in regard to chemically coded eating and drinking circuits, leave the issue of the relationship between deprivation-induced behavior and chemically induced behavior unresolved.

\section{REFERENCES}

DeGroot, J. The rat forebrain in stereotaxic coordinates. Verhandelinger Konenklyke Nederlandsche Academic van Wetenschappen, Natuurkunde, 1959, 2, 1-40.

Epstein, A. N. Reciprocal changes in feeding behavior produced by intra-hypothalamic chemical injections. American Journal of Physiology, 1960, 199, 969-974.

Grossman, S. P. Direct adrenergic and cholinergic stimulation of hypothalamic mechanisms. American Journal of Physiology, $1962,202,872-882$.

Grossman, S. P. A textbook of physiological psychology. New York: Wiley, 1967.

Levitt, R. A., \& Fisher, A. E. Failure of central anticholinergic brain stimulation to block natural thirst. Physiology \& Behavior, 1967, 2, 425-528.

Mountford, D. Drinking following carbachol stimulation of hippocampal formation or lateral ventricles. Psychonomic Science, 1969, 16, 124-125.

Routtenberg, A. Intracranial chemical injection and behavior: $A$ critical review. Behavioral Biology, 1972, 7, 601-641.

Singer, G., \& Kelley, J. Cholinergic and adrenergic interaction in the hypothalamic control of drinking and eating behavior. Physiology \& Behavior, 1972, 8, 885-890.

Singer, G., \& Montgomery, R. B. Specificity of chemical stimulation of the rat brain and other related issues in the interpretation of chemical stimulation data. Pharmacology, Biochemistry, \& Behavior, 1973, 1, 211-224.

Sommer, S. R., Novin, D., \& LeVine, M. Food and water intake after intrahy pothalamic injections of carbachol in the rabbit. Science, 1967, 156, 983-984.

Walker, H. M., \& Lev, J. Statistical inference. New York: Holt, Rinehart \& Winston, 1953.

Wise, R. A. Rebound eating following carbachol-induced drinking in rats. Physiology \& Behavior, 1972, 9, 659-661.

(Received for publication November 19, 1973.) 